\title{
Amyloid $\beta$-protein oligomers promote the uptake of tau fibril seeds potentiating intracellular tau aggregation
}

\author{
Woo Shik Shin ${ }^{1}$, Jing Di ${ }^{1}$, Qin Cao ${ }^{2}$, Binsen Li ${ }^{1}$, Paul M. Seidler ${ }^{2}$, Kevin A. Murray ${ }^{2}$, Gal Bitan ${ }^{1,3}$ and Lin Jiang ${ }^{1,3^{*}}$ (D)
}

\begin{abstract}
Background: Repeated failure of drug candidates targeting Alzheimer's disease (AD) in clinical trials likely stems from a lack of understanding of the molecular mechanisms underlying AD pathogenesis. Recent research has highlighted synergistic interactions between aggregated amyloid- $\beta(A \beta)$ and tau proteins in $A D$, but the molecular details of how these interactions drive AD pathology remain elusive and speculative.
\end{abstract}

Methods: Here, we test the hypothesis that A potentiates intracellular tau aggregation, and show that oligomeric A specifically exacerbates proteopathic seeding by tau. Using tau-biosensor cells, we show that treatment with sub-toxic concentrations of A $\beta$ oligomers, but not monomers or fibrils, "primes" cells, making them more susceptible to tau seeding. The treatment with $A \beta$ oligomers enhances intracellular tau aggregation in a dosedependent manner when the cells are seeded with either recombinant or brain-derived tau fibrils, whereas little or no aggregation is observed in the absence of $A \beta$-oligomer priming.

Results: Priming by A $\beta$ oligomers appears to be specific to tau, as $\alpha$-synuclein seeding is unaffected by this treatment. $A \beta$ oligomer-enhanced tau seeding also occurs in primary mouse neurons and human neuroblastoma cells. Using fluorescently labeled tau seeds, we find that treatment with A $\beta$ oligomers significantly enhances the cellular uptake of tau seeds, whereas a known tau-uptake inhibitor blocks the effect of A $\beta$ on tau uptake.

Conclusion: The ability of $A \beta$ to promote tau seeding suggests a specific and plausible mechanism by which extracellular $A \beta$ initiates a deleterious cascade that is unique to AD. These data suggest that the A $\beta$-mediated potentiation of tau uptake into cells should also be taken into account when designing A $\beta$-targeted therapeutics.

Keywords: Amyloid beta, Tau, Biosensor cell, Oligomer, Alzheimer's disease

\section{Background}

Amyloid plaques and neurofibrillary tangles (NFTs), comprising $\mathrm{A} \beta$ and hyperphosphorylated tau, respectively, are the two major hallmarks of Alzheimer's disease (AD) pathology [1-3]. The relationships among $A \beta$, tau, and neurodegeneration in $\mathrm{AD}$ are not fully understood $[4,5]$. Although the amyloid cascade hypothesis has posited that $\mathrm{A} \beta$ aggregation is the initiating pathologic event in $\mathrm{AD}[6,7]$, biomarker and pathology studies have shown a strong correlation between NFT accumulation, neurodegeneration, and clinical

\footnotetext{
* Correspondence: jianglin@ucla.edu

'Department of Neurology, David Geffen School of Medicine, UCLA, 635

Charles E Young Drive South, Los Angeles, CA 90095, USA

${ }^{3}$ Brain Research Institute, and Molecular Biology Institute, UCLA, Los Angeles, CA 90095, USA

Full list of author information is available at the end of the article
}

decline, whereas plaque pathology correlated poorly with AD progression [8-12]. Moreover, despite promising results in pre-clinical models, therapies that reduce plaque load have not yielded significant benefits in clinical trials for $A D$. The limited understanding of the link between $A \beta$ accumulation and tau deposition in $\mathrm{AD}$ is a key piece that is missing from our knowledge of the disease mechanism, and may factor into failures of existing $A \beta$ therapies in clinical trials.

The interplay between $A \beta$ and tau is exemplified in animal models and biomarker studies of AD patients [13-16]. Studies in animal models show synergistic enhancement of tau accumulation in the presence of $A \beta$ in the cortex of young mice overexpressing the frontotemporal-dementiaassociated variant P301L-tau. In wild-type mice, $\mathrm{A} \beta$ plaques enhance tau seeding and pathology $[17,18]$. Biomarker 
studies in patients concluded that the progression of $\mathrm{AD}$ dementia is driven by the synergistic interaction between $A \beta$ and tau [19-22]. This body of work provides the basis for our hypothesis that $A \beta$ and tau synergize to create a defining pathology in $\mathrm{AD}$, the details of which are the focus of our current study.

$\mathrm{A} \beta$ and tau aggregate to form small soluble oligomers, and large insoluble fibrils that are seen in $\mathrm{AD}$ and related diseases [14, 23]. Several studies have shown that oligomeric and fibrillar species contribute differently to disease progression. For example, soluble $A \beta$ oligomers are thought to be a major toxic agent in $\mathrm{AD}$ [24]. Tau oligomers and fibrils have been proposed to template the conversion of monomers into aggregates in recipient cells, leading to pathological spread in the brain [25-28]. Cell culture assays are useful tools for dissecting the contribution of specific assemblies in each pathological process. Experiments using primary neurons or neuronal cell lines have shown that application of $A \beta$ oligomers increased tau phosphorylation, demonstrating a link between $A \beta$ toxicity and tau pathology [29]. However, it is unclear how a direct interaction might occur between $\mathrm{A} \beta$ and tau in pathological tau seeding.

Here, we sought to explore how different $A \beta$ assemblies might contribute to the process of tau seeding. We investigated the relationship between different assemblies of $A \beta$-freshly prepared, oligomeric, and fibrillarand tau seeding using several cell-culture models, including FRET-based tau biosensor cells [30, 31], human neuroblastoma cells, and primary hippocampal neurons from transgenic mice expressing human P301S tau. We also explored the mechanism by which $A \beta$ oligomers affect cellular uptake of tau seeds. Our findings connect toxic $A \beta$ oligomers to tau seeding, a currently missing link in our understanding of AD pathology.

\section{Results}

Preparation of defined self-assembly states of $A \beta$ and tau To determine which forms of self-assembled or aggregated A $\beta$ might promote tau seeding, we first expressed and purified recombinant $A \beta$ and tau and prepared different selfassembled forms of each. Recombinant $A \beta$ (1-42) (Fig. 1a) was expressed and purified as described previously [32]. To eliminate pre-formed aggregates during purification, the protein was fractionated using size-exclusion chromatography (SEC), yielding a major peak with an apparent retention time of a trimer (Additional file 1: Figure S1a), which previously has been shown to consist of a mixture of monomers and small oligomers, defined as low molecular weight (LMW) $A \beta$ [33]. This LMW A $\beta$ showed a major band when analyzed by native-PAGE at $\sim 20 \mathrm{kDa}$ and a smeary band consistent with molecular weights ranging from 70 to $200 \mathrm{kDa}$ (Additional file 1: Figure S1b), likely representing the immediate self-assembly of $A \beta$ in the PBS solution.
Examining the preparation by electron microscopy (EM) showed occasional spherical structures, but mostly the species in freshly prepared $A \beta$ were too small to be observed by EM (Additional file 1: Figure S1c). The freshly prepared $\mathrm{A} \beta$ was then quiescently incubated at $37^{\circ} \mathrm{C}$ at $10 \mu \mathrm{M}$ in $\mathrm{PBS}$ to generate different self-assembly states. We monitored the self-assembly of $A \beta$ by thioflavin $T$ (ThT) fluorescence (Fig. 1c). After incubation for $18 \mathrm{~h}$, native PAGE showed a smeary band consistent with molecular weight $\geq$ $250 \mathrm{kDa}$, suggesting the presence of high molecular weight oligomers composed of $\geq 55$ copies of the $\mathrm{A} \beta$ peptide ( $4.5 \mathrm{kDa}$ per monomer) (Additional file 1: Figure S1b). EM images of these samples, termed oligomeric $A \beta$, showed abundant quasi-spherical structures with diameters ranging between 20 and $60 \mathrm{~nm}$ (Additional file 1: Figure S1d,e). Finally, after $\sim 100 \mathrm{~h}$ of incubation, $\mathrm{A} \beta$ formed typical, unbranched amyloid fibrils (Fig. 1c). The native PAGE lane for the fibril sample shows no bands (Additional file 1: Figure S1b), indicating a complete conversion of the samples into insoluble fibrils unable to migrate on the gel, which is also confirmed by the plateau in the ThT kinetics (Fig. 1c).

Recombinant tau repeat domain (RD, Fig. 1b) was used to generate fibrillar seeds in PBS containing $20 \mathrm{mM}$ DTT at $37^{\circ} \mathrm{C}$. We did not use aggregation inducers, such as heparin, because of their potential effect on intracellular tau seeding/aggregation, complicating data interpretation. Under these conditions, following a lag phase of $\sim 30 \mathrm{~h}$, a sharp increase in ThT fluorescence was observed, suggesting tau fibril formation. In agreement with these results, EM images showed no aggregates at 0 -h incubation and elongated fibrils after $100 \mathrm{~h}$ of incubation (Fig. 1d). In contrast to $A \beta$, for which quasi-spherical oligomers were observed at intermediate time points (from 10 to $30 \mathrm{~h}$ ), we did not observe oligomers of tau RD by EM.

\section{$A \beta$ oligomers promote tau aggregation seeded by tau $\mathrm{RD}$, full-length tau, or brain extracts from a tauopathy mouse model}

Following the preparation of different aggregated species of $A \beta$, we assessed their impact on tau seeding using the HEK293T tau biosensor cell line developed by Diamond and co-workers for monitoring and quantifying intracellular tau aggregation and seeding [34, 35]. Expressing tau RD containing the disease-associated P301S substitution fused to either CFP or YFP, the biosensor cells produce a FRET signal upon aggregation of tau, which can be quantified using flow cytometry. As a control, we first tested the effect of $A \beta$ on the biosensor cells in the absence of tau seeds. The cells were treated with up to $200 \mathrm{nM}$ freshly prepared, oligomeric, or fibrillar $\mathrm{A} \beta$ without the addition of transfection reagent, and FRET was quantified by flow cytometry. As expected, minimal tau aggregation (integrated FRET density (IFD): < 10, 


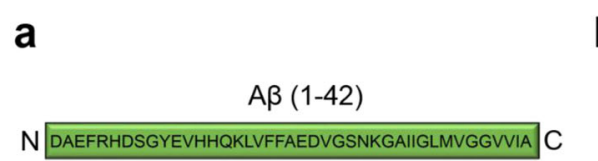

b
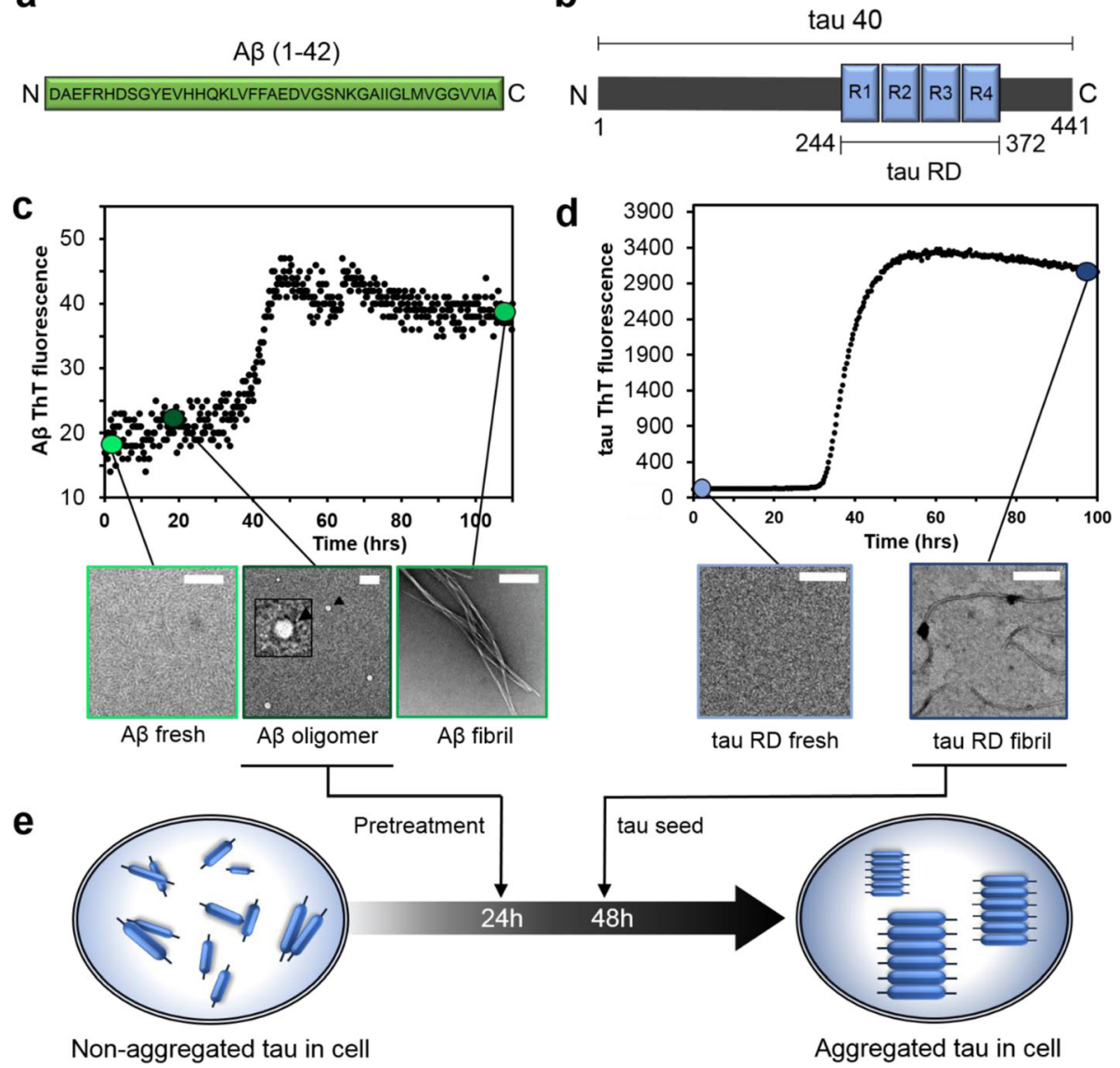

Fig. 1 Characterization of $A \beta$ and tau self-assembly. a The sequence of the $A \beta(1-42)$. b A schematic of full-length tau (tau40, residue 1-441), which contains four tandem repeats (R1-R4) in the repeat domain (tau RD, residues 244-372). c ThT fluorescence (upper panel) and EM images (lower panel) of $A \beta 42$ at different incubation times demonstrate that freshly prepared A 422 self-assembles and aggregates into spherical oligomers at $18 \mathrm{~h}$ and unbranched fibrils at $100 \mathrm{~h}$. The inset highlights the spherical shape of the A 42 oligomers. The scales bar denotes $200 \mathrm{~nm}$. d ThT fluorescence (upper panel) and EM images (lower panel) of tau RD. e A schematic representation of the timeline used for seeding experiment. Different A 342 self-assembly states and tau seeds were sequentially added to cells at $24 \mathrm{~h}$ and $48 \mathrm{~h}$, respectively

Additional file 1: Figure S2) was observed after $48 \mathrm{~h}$, and even after 2 weeks (Additional file 1: Figure S3), demonstrating that neither form of $A \beta$ induced tau aggregation without the addition of tau seeds in these cells. Our additional control experiments using tau RD seeds on their own, again not mixed with transfection reagents or any other additive, showed no measurable intracellular aggregation in the biosensor cells (Fig. 2a, b).

Next, to test whether $A \beta$ facilitates tau seeding, biosensor cells were seeded with sonicated tau RD fibrils $24 \mathrm{~h}$ after adding freshly prepared, oligomeric, or fibrillar $\mathrm{A} \beta$, and the resulting levels of intracellular tau aggregation were quantified after an additional 48-h incubation. Treating cells with $100-500 \mathrm{nM} A \beta$ oligomers $24 \mathrm{~h}$ before addition of tau RD seeds led to a significant, dose-dependent increase in intracellular tau aggregation. The aggregates were visualized as bright puncta by fluorescence microscopy (Fig. 2a, white arrows) and were quantified by flow cytometry (Fig. 2b).
Treatment of the cells with $\mathrm{A} \beta$ fibrils also promoted tau aggregation, yet to a substantially lower extent $(\sim 10 \%)$ than $A \beta$ oligomers. Treatment with freshly prepared $A \beta$ or a mixture of freshly prepared $A \beta$ and $A \beta$ fibrils did not promote tau aggregation.

We further asked whether $A \beta$ oligomers could facilitate intracellular tau aggregation seeded not only by the tau RD, but also by full-length recombinant human tau (tau40) or by brain extracts from transgenic PS19 mice expressing human 1N4R tau containing the P301S substitution [36]. Addition of tau40 fibrils at $100-500 \mathrm{nM}$ induced a low level of tau aggregation in the biosensor cells (Fig. 2c, blue curve). Pre-treatment of the cells with $500 \mathrm{nM} \mathrm{A} \beta$ oligomers doubled the seeding effect of tau40 fibrils (red curve). Following the same trend, pretreatment with $A \beta$ oligomer led to a small increase in seeding by freshly prepared tau 40 (green and black curves). When we quantified tau aggregation seeded by 
a


C

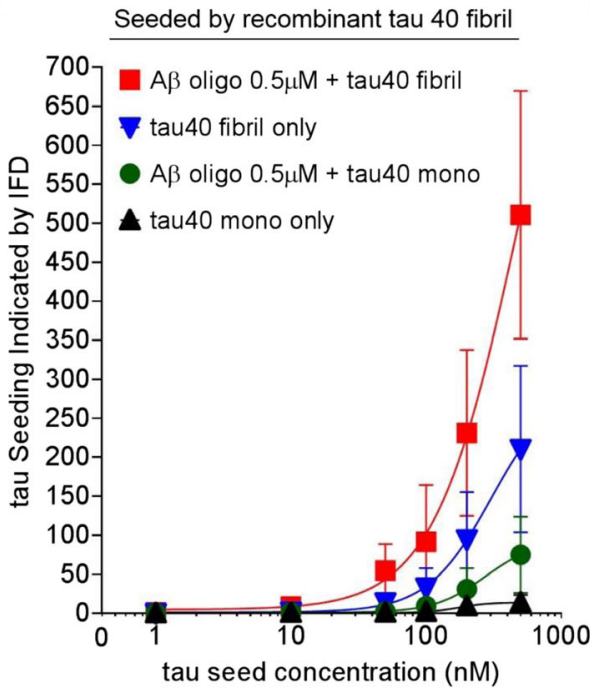

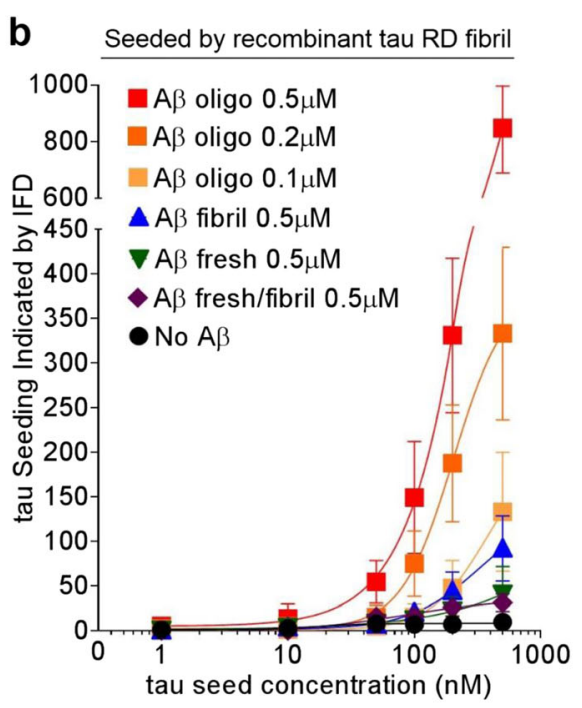

d

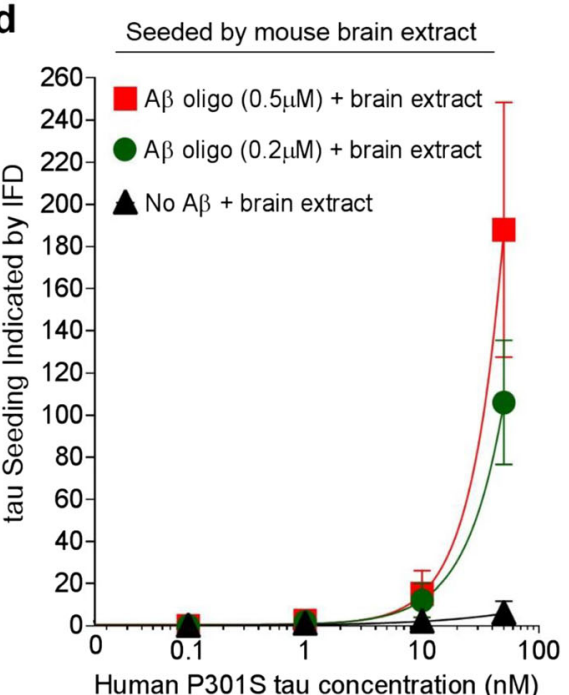

Fig. 2 Pretreatment with $A \beta$ oligomers but not $A \beta$ freshly prepared or $A \beta$ fibrils promotes tau seeding. a Fluorescence microscopy images of taubiosensor cells treated with $500 \mathrm{nM}$ of freshly prepared, oligomeric, or fibrillar A $\beta$ followed 24-h later by $200 \mathrm{nM}$ tau seeds. Tau aggregates are indicated by white arrows. The scale bar denotes $50 \mu \mathrm{m}$. b-d Flow-cytometry-based FRET quantification of intracellular tau aggregation seeded by recombinant tau RD fibrils (b), tau 40 fibrils (c), or PS19 mouse brain extracts (d). The enhancement by A $\beta$ pretreatment is much stronger for $A \beta$ oligomers (red), compared to $A \beta$ fresh (green) and fibrils (blue), and occurs in a dose-dependent manner. c $A \beta$ promotes intracellular tau aggregation seeded by full-length tau. $\mathbf{d}$ A $\beta$ promotes seeding with brain extract from mice expressing human full-length P301S tau. ELISA was used to quantify human tau expressed in mouse brain extracts. The data are presented as mean \pm SD $(n=6-9)$

PS19-mouse brain extracts, containing human 1N4R P301S tau, priming with 200 or $500 \mathrm{nM} \mathrm{A} \beta$ oligomers dose-dependently increased tau seeding by 15 and $>30$ fold, respectively, compared to brain extract added without $A \beta$ pre-treatment (Fig. 2d). Representative fluorescence microscopic images of these cells are shown in Additional file 1: Figure S4. Though tau RD, tau40, and PS19 brain extracts had different seeding capacities, in all cases, priming with $\mathrm{A} \beta$ oligomers substantially enhanced the seeding of tau.

We also assessed whether the priming of the biosensor cells by $\mathrm{A} \beta$ oligomers required a preincubation time, or could be achieved immediately. When tau seeds were added to the cells simultaneously with $\mathrm{A} \beta$ oligomers, we did not observe promotion of tau seeding (Additional file 1: Figure S5), suggesting that sufficient incubation time $(\sim 24 \mathrm{~h})$ of the pretreatment was needed for $\mathrm{A} \beta$ oligomer to prime the cells for enhancing tau seeding.

\section{$A \beta$ oligomers do not facilitate $\boldsymbol{\alpha}$-synuclein seeding}

An important mechanistic question is whether $A \beta$ oligomers promote seeding of tau specifically or could facilitate seeding of other amyloidogenic proteins in a non-specific manner. To address this question, we examined the effect 
of $A \beta$ oligomers on seeding of $\alpha$-synuclein, whose aggregation has been associated with Parkinson's disease and other synucleinopathies [37]. Similar to tau, $\alpha$-synuclein pathology has been reported to accumulate through brain regions, and $\alpha$-synuclein aggregates often are found in the $\mathrm{AD}$ brain [38]. Using HEK293T biosensor cells coexpressing CFP- or YFP-fused A53T- $\alpha$-synuclein, we added up to $1 \mu \mathrm{M}$ sonicated $\alpha$-synuclein fibrils in the absence or presence of $A \beta$-oligomer priming. In contrast to the experiments using tau seeds and tau-biosensor cells, we did not observe an enhancement in the seeding of $\alpha$ synuclein in $\alpha$-synuclein-biosensor cells pre-treated with up to $200 \mathrm{nM} \mathrm{A} \beta$ oligomers compared to cells that were not pre-treated (Additional file 1: Figure S6), suggesting that the seeding enhancement by $A \beta$ oligomers is specific to tau.

\section{$A \beta$ oligomers facilitate tau seeding in primary neurons and human neuroblastoma cells}

The FRET-based biosensor cells are a convenient tool for sensitive quantification of tau or $\alpha$-synuclein seeding, but may not fully represent seeding in neurons. Therefore, we sought to determine whether $A \beta$ oligomers facilitate tau seeding in primary mouse neurons and a human neuroblastoma cell line. Primary hippocampal neurons were isolated from the PS19 mice and treated with tau seeds with or without $A \beta$-oligomer priming. Because this cellular system does not express fluorescently labeled tau and is not applicable to FRET-based flow cytometry, we used confocal microscopy instead to qualitatively assess seeding (Fig. 3a). When immunostained with antibodies HT7 or AT8, which recognize total human tau and phosphorylated tau (at Ser 202 and Thr 205), respectively [39], primary hippocampal neurons treated with $500 \mathrm{nM}$ tau RD seeds alone showed a few bright fluorescent puncta, while untreated cells showed no such puncta. Treatment with $200 \mathrm{nM}$ A $\beta$ oligomers $24 \mathrm{~h}$ before the addition of tau seeds led to a marked increase in red fluorescent puncta (indicated by white arrows, Fig. 3a, bottom panels).

To quantitatively measure tau seeding in neuronal cells, we established a cellular assay in which human SH-SY5Y neuroblastoma cells were incubated with tau seeds with or without pre-treatment with $A \beta$ oligomers. The cells were washed extensively with PBS to remove any tau and $A \beta$ that might have been present in the culture media, lysed, and their lysates centrifuged to remove insoluble material and cell debris. The clarified cell lysates (tau concentration of $26 \mathrm{nM}$, measured by Western blot and ELISA, Additional file 1: Figures S7S8) were added to the tau biosensor cells for measurement of seeding (Fig. 3b). Priming the SH-SY5Y cells with $\mathrm{A} \beta$ oligomers yielded $>4$-fold increase in tau aggregation in biosensor cells compared to the SH-SY5Y cells without $A \beta$-oligomer priming (Fig. 3c).

\section{$A \beta$ oligomers enhance tau seeding by promoting seed internalization}

To visualize the cellular uptake of tau seeds, we conjugated fluorescein to tau RD (FITC-tau), allowed the protein to form fibrils, and prepared seeds. We then primed SH-SY5Y cells with $200 \mathrm{nM}$ freshly prepared, oligomeric, or fibrillar $\mathrm{A} \beta$ for $24 \mathrm{~h}$, followed by seeding with $500 \mathrm{nM}$ FITC-tau fibrils. After extensive washing with PBS, the cells were inspected by fluorescence microscopy (Fig. 4a) and seeding was quantified using flow cytometry (Fig. 4b). Without A $\beta$ oligomer priming, $12 \pm 3 \%$ of the SH-SY5Y cells showed internalized FITC-tau seeds. Treatment with freshly prepared $\mathrm{A} \beta(12 \pm 4 \%)$ or $\mathrm{A} \beta$ fibrils $(16 \pm 3 \%)$ did not affect FITC-tau internalization. Priming with oligomeric $A \beta$ increased the uptake of FITC-tau seeds significantly to $64 \pm 8 \%$, suggesting that $A \beta$ oligomers facilitated tau seeding by promoting the internalization of the seeds. A $\beta$-promoted internalization of tau seeds was also observed in wild-type mouse primary neurons (Additional file 1: Figure S9).

Lastly, to investigate whether inhibition of tau seed uptake could block $A \beta$ promoted tau seeding, we tested heparin, a known tau uptake inhibitor [40], in the tau biosensor cells. Flow-cytometry analysis revealed that increasing concentrations of heparin, 1 to $50 \mu \mathrm{M}$, decreased the $\mathrm{A} \beta$-promoted tau seeding in a dose-dependent manner (Fig. 4c). We confirmed that heparin inhibits tau-seed uptake using wild-type HEK293T cells instead of the biosensor cells because of spectral overlap between the fluorescence of FITC and YFP/ CFP. Similar to the SH-SY5Y cells, A $\beta$ oligomers increased the internalization of FITC-tau seeds in wild-type HEK293T cells $>5$-fold compared to untreated cells (Fig. 4d). Addition of $10 \mu \mathrm{M}$ heparin reduced tau internalization to the level of non-primed cells.

\section{Discussion}

Studies in rodents and on clinical specimen have demonstrated a synergistic interaction between $A \beta$ and tau in the development of $\mathrm{AD}$ [13-15], but the mechanistic details of this synergy have yet to be fully elucidated. In this study, we focused on tau seeding, which is correlated to AD progression, and investigated how $A \beta$ affects this seeding process. Using biochemical and cellular assays, we aimed here to dissect which self-assembly states of $A \beta$ contribute to tau seeding and aggregation. We found that tau seeding is greatly enhanced by $A \beta$ oligomers, but not by freshly prepared $A \beta$ or $A \beta$ fibrils. The enhancement of seeding was not limited to a particular construct of tau and was apparent for seeds that were prepared from tau RD, full-length tau, and mouse brain extract containing human P301S tau. In addition, seeding enhancement was not restricted to a particular cell type and was observed in multiple cellular systems including HEK293T cells, human neuroblastoma cells, and mouse primary hippocampal neurons. Our data illustrate that 100 $200 \mathrm{nM}$ of $\mathrm{A} \beta$ oligomers effectively facilitate tau seeding 
a
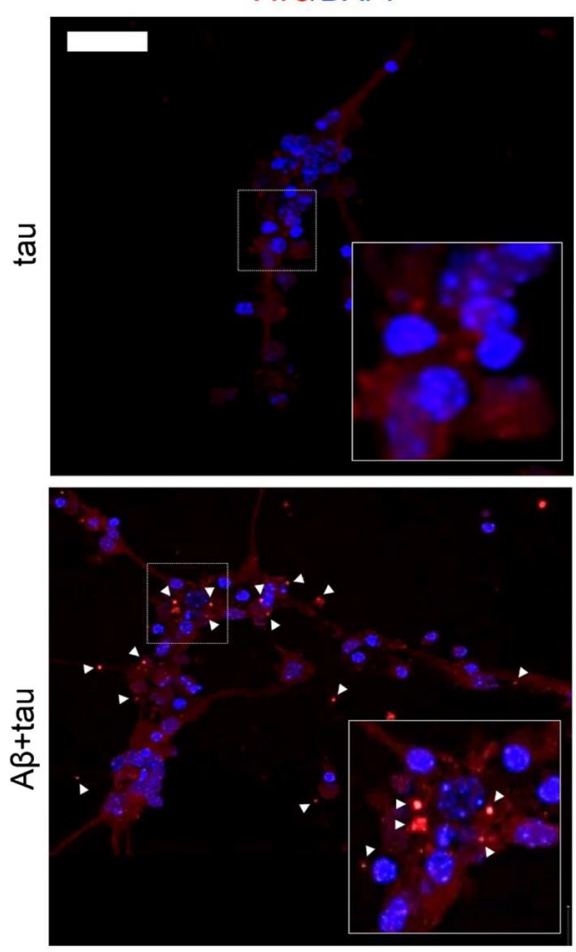

b

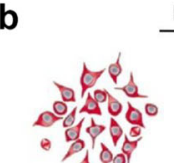

SH-SY5Y human Neuroblastoma cell
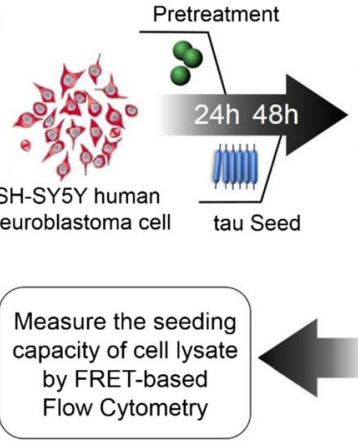

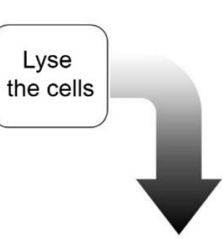

Quantify tau concentration of supernatant of cell lysate by ELISA
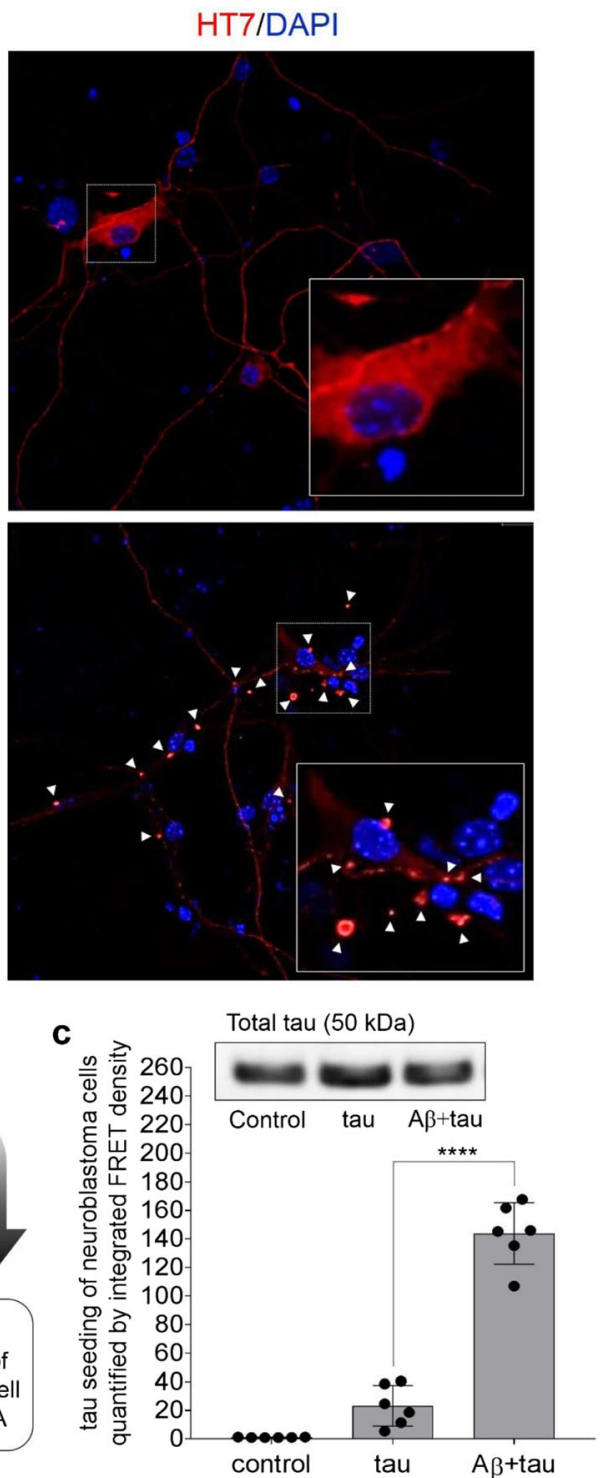

Fig. $3 \mathrm{~A} \beta$ oligomers promote tau seeding in primary hippocampal neurons and human neuroblastoma cells. a $500 \mathrm{nM}$ tau seeds were added to primary hippocampal neurons from PS19 mice with (top panels) or without (bottom panels) $24 \mathrm{~h}$ pretreatment of $200 \mathrm{nM}$ A $\beta$ oligomers. Immunostaining with tau antibodies HT7 (left) or AT8 (right) was performed $24 \mathrm{~h}$ after the addition of tau seeds. Nuclei were stained with DAPI (blue). The scale bar denotes $20 \mu \mathrm{m}$. Tau inclusions are highlighted by white arrows. $\mathbf{b}$ A schematic representation of the assays used to measure A $\beta$ promotion of tau seeding in neuroblastoma SH-SY5Y cells. Cells were treated with A $\beta$ oligomers at $24 \mathrm{~h}$ and tau seeds at $48 \mathrm{~h}$ and then lysed at $72 \mathrm{~h}$. ELISA was used to measure tau concentration in the lysates, then seeding was measured in the tau-biosensor cells, and the seeding capacity of the supernatant was measured by FRET-based flow cytometry. c Quantification of tau seeding in SH-SY5Y cells with or without pretreatment with A $\mathrm{B}$ oligomers. The representative western blot above the bar graph shows that a similar amount of total tau in the SH-SY5Y cell lysates was used in each case. Data are mean $\pm \operatorname{SD}\left(n=6,{ }^{* * *} p<0.0001\right.$, one-way ANOVA)

(Additional file 1: Figures S10 and S11), which are below the micromolar concentrations of $\mathrm{A} \beta$ oligomers typically used in cellular toxicity studies $[41,42]$. Notably, these concentrations are in the same range as the reported physiological $\mathrm{A} \beta$ concentration, between $42 \mathrm{nM}$ and $195 \mathrm{nM}$ in $\mathrm{AD}$ patients $[43,44]$.

Previous studies have proposed that soluble A $\beta$ oligomers are the primary effector of neurotoxicity in $\mathrm{AD}$ by inducing cellular stress through non-specific mechanisms, including oxidative stress and pore formation [45, 46]. At micromolar concentrations, our $\mathrm{A} \beta$-oligomer preparation with similar morphology to previous studies [41, 42] also exhibited cytotoxicity to multiple cell types, including primary neurons [47]. We demonstrate here that at physiologically relevant concentrations, $\mathrm{A} \beta$ oligomers exhibit a heretofore unknown deleterious activity-facilitation of 

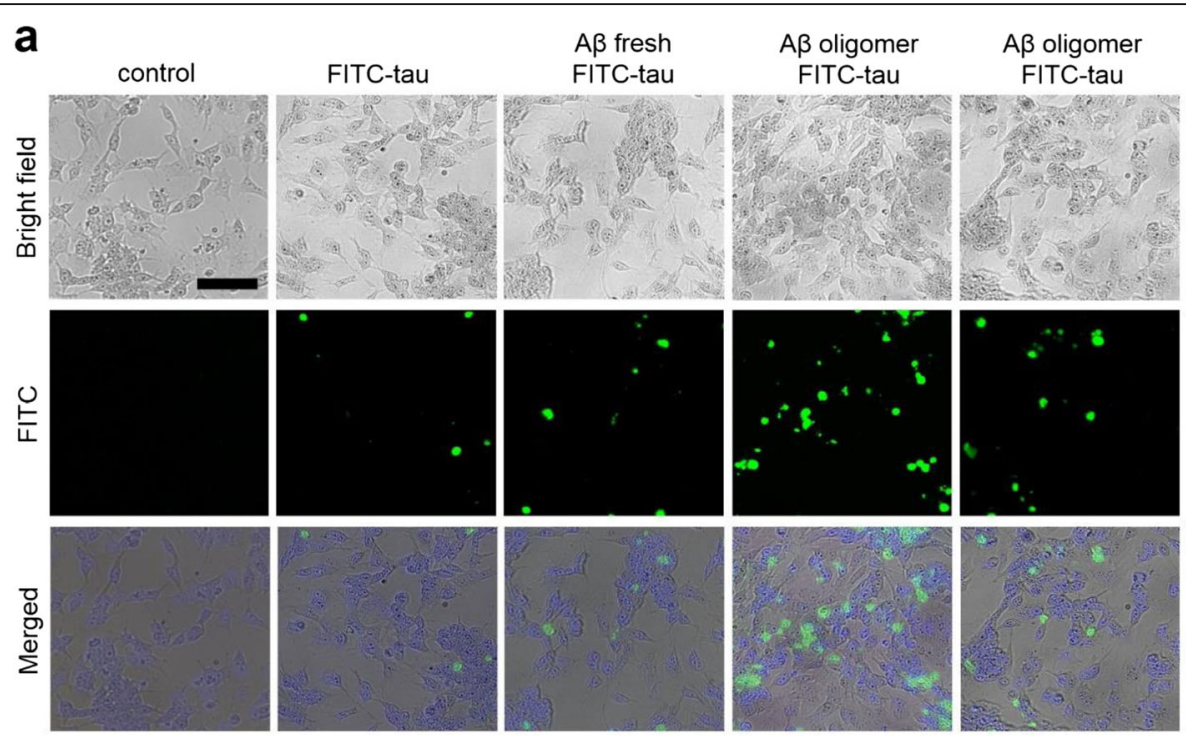

b

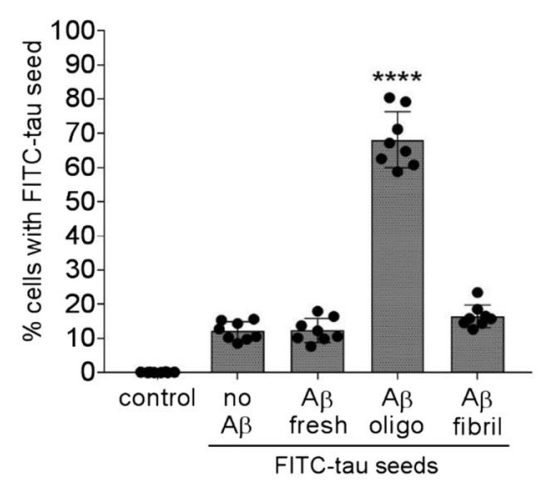

d

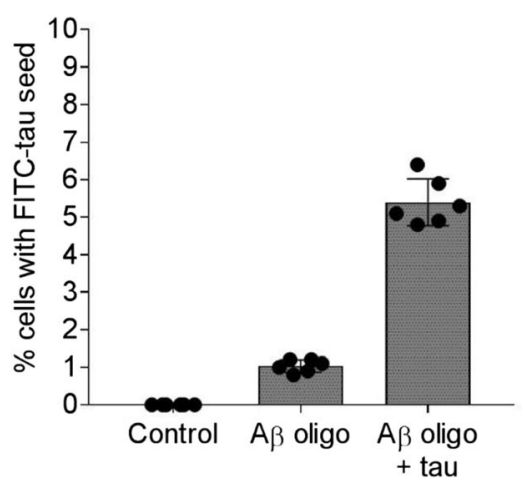

$\mathbf{C}$



e

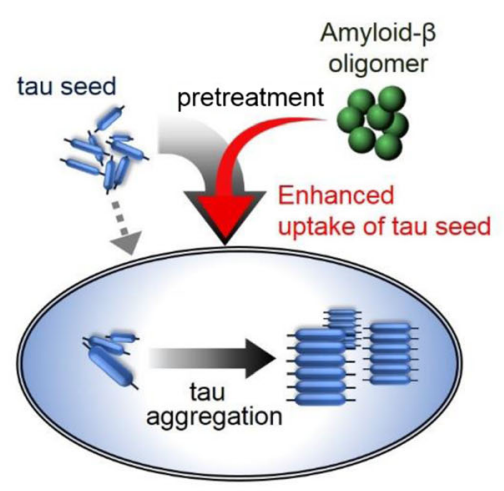

Fig. $4 \mathrm{~A} \beta$ oligomers potentiate intracellular tau aggregation by promoting tau seed uptake. a, b Fluorescence-microscopy images (a) and flow cytometry-based quantification (b) of internalized fluorescein-labeled tau seed (500 nM, green) in SH-SY5Y cells with or without pretreatment with 200 nM freshly prepared, oligomeric, or fibrillar AB. Untreated SH-SY5Y cells were used as a negative control. After extensive PBS washing, cells were fluorescently imaged and subsequently harvested with trypsin treatment for flow cytometry. The data are presented as mean \pm SD $(n=8$, ${ }^{* * * *} p<0.0001$, one-way ANOVA). The scale bar denotes $20 \mu \mathrm{m}$. c Various concentrations of heparin, from $10 \mathrm{nM}$ to $50 \mu \mathrm{M}$, were applied to HEK293T tau biosensor cells $1 \mathrm{~h}$ before A $\beta$ pretreatment, and tau seeding was quantified as integrated FRET density using flow cytometry. $\mathbf{d}$ The same trend of $A \beta$-oligomer mediated enhancement of labeled tau seed internalization in HEK293T cells. Heparin was added $1 \mathrm{~h}$ before A $\beta$ pretreatment. The data are presented as mean \pm SD $(n=6)$. e A diagram of A $\beta$-promoted tau seeding

tau seeding, providing a plausible mechanism that links $\mathrm{A} \beta$ to the stimulation of tau pathology, as is the case in AD. Moreover, the data provides a possible explanation to the sharp difference between the high prevalence of $\mathrm{AD}$ in the aging population as opposed to other tauopathies, which are much rarer. $A \beta$ oligomers are unique to $A D$ 
and are not known to be part of the pathological mechanism in rare tauopathies. Thus, we propose that AD is not just a coincidental combination of two unrelated toxic proteoforms, aggregated $A \beta$ and tau, but rather is the manifestation of a synergistic exacerbation of tau spreading by $A \beta$ oligomers. In agreement with this idea, a recent study demonstrated that suppression of tau gene expression was substantially less effective at rescuing neuronal impairment in transgenic mice expressing both human $A \beta$ and tau compared to mice expressing tau alone [48].

Our data demonstrate that the A $\beta$-oligomer promotes seeding that is apparently unique to tau protein. $\alpha$ Synuclein seeding, which is a similar process to that of tau, is not facilitated by $A \beta$ oligomers. The specific activation of tau seeding by $A \beta$ oligomers may explain not only the higher prevalence but also mechanistic aspects of AD compared to other tauopathies, such as primary age-related tauopathies (PART), the NFTs of which are indistinguishable from those of $\mathrm{AD}$ [49]. PART, which does not involve any $A \beta$ pathology, has characteristic NFT pathology localized to the medial temporal lobe with low levels of tau spreading to other brain regions [50]. In comparison, $A D$, which involves both $A \beta$ and tau, is characterized by the accumulation of NFT pathology in broader brain regions. These different capacities of NFT accumulation between AD and PART may reflect differences in the ability of tau to spread in $A D$ by $A \beta$ oligomers, whereas in the absence of $A \beta$ oligomers, the spread of tau is slower and more limited to specific brain regions, as in the case of PART.

$A \beta$ oligomers could promote tau seeding by several mechanisms. One possible mechanism is the formation of $A \beta$ channels/pores in the cell membrane through which tau seeds would enter. Multiple reports have suggested that $A \beta$ oligomers could exert neurotoxicity by forming pores or channel-like structures in the plasma membrane $[41,51,52]$. Formation of $\mathrm{A} \beta$ pores likely occurs over a short period of time ( 1 to $2 \mathrm{~h}$ ) [53]. Our experiments suggest that sufficient incubation time with $A \beta$ oligomers is needed for enhancement of tau seeding as pretreatment times of 0,1 , and $3 \mathrm{~h}$ also show no enhancement of tau seeding (Additional file 1: Figure S5). In addition, if tau seeding was facilitated by $\mathrm{A} \beta$-oligomer pore formation in the plasma membrane, enhancement of $\alpha$-synuclein seeding would be expected, but $A \beta$ pretreatment of $\alpha$-synuclein biosensor cells show no enhancement of $\alpha$-synuclein seeding (Additional file 1: Figure S6). In short, our studies suggest the observed promotion by $A \beta$ oligomers is not likely to be directly related to pore formation.

Another possible mechanism is cross-seeding of intracellular tau aggregation by $A \beta$ oligomers, as proposed previously [54]. However, none of the A $\beta$ self-assemblies induced tau aggregation when tau seeds were not added
$24 \mathrm{~h}$ later, and thus, it is unlikely that $\mathrm{A} \beta$ cross-seeded tau aggregation in our assays. Taken together, our data show that the $A \beta$-mediated increase in tau seeding is a specific process that neither involves cross-seeding between $A \beta$ and tau nor the formation of pores in the plasma membrane by $A \beta$ oligomers, but rather that $A \beta$ oligomers prime the cells for tau internalization by some other currently unknown mechanism.

Using our cellular assays, we demonstrated that pretreatment with sub-toxic concentrations of $A \beta$ oligomers significantly enhances the cellular uptake of tau seeds, leading to a substantial increase of intracellular tau aggregation. This potentiation is inhibited by the addition of heparin, a tau uptake inhibitor (Fig. 4e). We reach this finding by using more physiologically relevant cellular assays of tau seeding, compared to previous cellular studies which typically have used transfection agents, such as lipofectamine, to achieve efficient transduction of tau seeds into cells [13]. Using such transfection agents allows for sensitive measurements of seeding, but does not reflect tau seeding as it would occur in vivo. In contrast, artificial transfection reagents were not utilized in our study, enabling us to discover the seedingenhancing capability of $A \beta$ oligomers in a more physiologically relevant way. In future studies, in addition to revealing a potentially relevant heretofore unknown mechanism that may underlie the propagation of tau pathology in $\mathrm{AD}$, the cellular assays we developed should be suitable for high-throughput compound screening for drugs targeting $A \beta$-enhanced tau seeding. New drug design and development based on blocking $A \beta$-promoted tau seeding by inhibiting $A \beta$-oligomer-cell interactions [55], preventing tau seed uptake, or a combination of both could present new opportunities with greater promise to delay or even halt $\mathrm{AD}$ progression.

\section{Conclusion}

In our study, we demonstrated how different species of $\mathrm{A} \beta$ self-assemblies (oligomers, fibrils, etc.) might contribute to the process of tau aggregation. We investigated that the ability of oligomeric $A \beta$ to promote tau seeding suggests a specific and plausible mechanism by which extracellular $A \beta$ initiates a deleterious cascade that is unique to $\mathrm{AD}$ using several cell-culture models, including FRET-based tau biosensor cells, human neuroblastoma cells, and primary hippocampal neurons from transgenic mice expressing human P301S tau. We also explored the mechanism by which $A \beta$ oligomers affect cellular uptake of tau seeds. Our data connect toxic $A \beta$ oligomers to tau seeding, a currently missing link in understanding of $\mathrm{AD}$ pathology and suggest that the $\mathrm{A} \beta$ mediated potentiation of tau uptake into cells should also be taken into account when designing $A \beta$-targeted therapeutics. 


\section{Materials and methods \\ Animals}

Animal care was conducted in compliance with the US Public Health Service Guide for the Care and Use of Laboratory Animals, and the procedures were approved by the Institutional Animal Care and Use Committee at the University of California, Los Angeles. Eight-month-old P301S (PS19) transgenic mice on (C57BL/6 x C3H) F1 background and wild-type mice were used for the study.

\section{$A \beta$ (1-42) expression and purification}

A $\beta$ (1-42) was expressed and purified as described previously [32]. Briefly, Escherichia coli BL21 plyS (DE3) cells were transformed with a plasmid encoding $A \beta$ (1-42) conjugated to maltose binding protein (pET28a-MBP$A \beta 42$ ). The expression of the fusion protein MBP-A $\beta 42$ was induced with $1 \mathrm{mM}$ of isopropyl- $\beta$-D-thiogalactopyranoside (IPTG) at $30^{\circ} \mathrm{C}$ for $4 \mathrm{~h}$. The culture was harvested and washed. The denatured fusion protein was purified using a HisTrap HP column (GE healthcare). After overnight dialysis, the fusion protein was cleaved overnight by TEV protease. The uncleaved protein and TEV were removed using $\mathrm{Ni}^{2+}$ affinity chromatography. The A $\beta$ (1-42) in the flow-through was purified by RPHPLC and lyophilized. To ensure the homogeneity of the $A \beta$ sample, the lyophilized powder was dissolved in 60 $\mathrm{mM} \mathrm{NaOH}$ and fractionated by SEC (GE, Superdex 200 Increase) in $20 \mathrm{mM} \mathrm{NaOH}$ to eliminate pre-formed $\mathrm{A} \beta$ aggregates. The final concentration was determined by a BCA assay, and the stock was stored in $-80^{\circ} \mathrm{C}$.

\section{Tau expression and purification}

Human tau RD (residues 244-372) and full-length tau (tau40, residues 1-441) were expressed and purified as described previously [56]. Briefly, for the expression of tau RD, BL21 (DE3 GOLD) competent cells and a pNG2 vector was used. Protein expression was induced by addition of $0.5 \mathrm{mM}$ IPTG for $3 \mathrm{~h}$ at $37^{\circ} \mathrm{C}$, and the cells were lysed by sonication. Cell lysates were then boiled for $20 \mathrm{~min}$ and centrifuged to remove all insoluble proteins. The remaining soluble protein was purified using a HighTrap SP ionexchange column (GE Healthcare), and fractions were analyzed by SDS-PAGE/Coomassie blue staining. Enriched fractions were further purified using a HiLoad 16/600 Superdex 75 SEC column (GE Healthcare). Purified tau was concentrated to $50-100 \mathrm{mg} / \mathrm{ml}$ and stored at $-80^{\circ} \mathrm{C}$.

For the expression of human tau40, a C-terminal His-tag was used. After IPTG induction, the cells were harvested and collected. The protein was purified using a HisTrap HP column and then purified by ion-exchange chromatography and SEC as described for tau RD.

\section{Thioflavin T (ThT) kinetics of amyloid aggregation of $A \beta$} and tau

Before the ThT kinetics assay, freshly SEC-fractionated $\mathrm{A} \beta$ was mixed with $60 \mathrm{mM} \mathrm{HCl}$ to neutralize the $\mathrm{NaOH}$ in the stock solution. After 3-min sonication, the $A \beta$ sample was diluted in PBS to a final concentration of $10 \mu \mathrm{M}$ and $30 \mu \mathrm{M}$ ThT (CalbioChem) was added. The reaction mixture was filtered through a $0.2-\mu \mathrm{m}$ filter, split into 3-4 replicates, and immediately placed in a Corning 96-well Nonbinding plate (black, nonbinding surface microplate). The ThT fluorescence signal was measured every $5 \mathrm{~min}$ in quiescent conditions using a Fluostar Omega plate reader (BMG Labtech, Offenburg, Germany) with excitation and emission wavelengths of 440 and $490 \mathrm{~nm}$, respectively, at $37^{\circ} \mathrm{C}$.

Freshly purified tau RD and tau 40 were diluted in PBS containing $2 \mathrm{mM}$ DTT, $40 \mu \mathrm{M}$ ThT to a final concentration of $250 \mu \mathrm{M}$ in the absence of any aggregation inducers (i.e., heparin). The reaction mixture was split into 3-4 replicates and placed in 96-well plates (Corning 3881). ThT fluorescence intensity was measured every 15 min with double orbital shaking at $37^{\circ} \mathrm{C}$ in the same plate reader until a plateau was reached.

\section{Measurement of tau seeding using HEK293T biosensor cells}

Tau RD P301S FRET Biosensor (ATCC CRL-3275) cells were cultured and analyzed as described previously [31]. The cells were grown in DMEM (Dulbecco's modifications of Eagle's medium with L-glutamine and $4.5 \mathrm{~g} / \mathrm{l}$ glucose) supplemented with fetal bovine serum (FBS), 100 units/ml of penicillin $\mathrm{G}$, and $0.1 \mathrm{mg} / \mathrm{ml}$ of streptomycin sulfate, in a humidified atmosphere of a $5 \% \mathrm{CO}_{2}$ at $37^{\circ} \mathrm{C}$. Trypsintreated HEK293T cells were plated on collagen-coated flat 96-well plates at a density of $2.5 \times 10^{4}$ cells/well in $200-\mu \mathrm{l}$ culture medium and incubated at $37^{\circ} \mathrm{C}$ in $5 \% \mathrm{CO}_{2}$. After $24 \mathrm{~h}$, the cells were treated with different self-assembly states of $A \beta$ or with media alone. Tau fibrils (tau RD, tau 40 and mouse brain extract) were diluted with Opti-MEM (GIBCO) and sonicated for $10 \mathrm{~min}$ in an ultrasonic water bath. Twenty-four hours after the treatment with $A \beta$, the culture media were replaced with fresh media containing the tau seeds. Tau aggregation in the biosensor cells was visualized at $72 \mathrm{~h}$ by fluorescence microscopy using green channel (ex: 485; em: 520). At $96 \mathrm{~h}$, the cells were harvested after extensive washing and treatment with trypsin. The harvested cells were prepared in $200 \mu \mathrm{l}$ chilled buffer (HBSS, 1\% FBS, 1 mM EDTA) and then stored at $4{ }^{\circ} \mathrm{C}$ until they were analyzed by FRET-based flow cytometry.

\section{Measurement of a-synuclein seeding using HEK293T biosensor cells}

$\alpha$-synuclein biosensor cells (a gift from Marc Diamond, UTSW) [30] were used for the study. Cells were grown 
in same DMEM growth media and $2.5 \times 10^{4}$ cells were plated on collagen-coated flat 96-well plates. After $24 \mathrm{~h}$, the cells were treated with $200 \mathrm{nM} \mathrm{A} \beta$ oligomers followed by addition of sonicated $\alpha$-synuclein fibrils at $48 \mathrm{~h}$. The preparation of recombinant $\alpha$-synuclein fibrils was performed as described previously [57]. $\alpha$-Synuclein seeding was visualized at $72 \mathrm{~h}$ by florescence microscopy, and at $96 \mathrm{~h}$, the cells were harvested and prepared for FRET-based flow cytometry.

\section{Flow cytometry and data analysis of tau and a-synuclein seeding}

Intracellular protein aggregation of tau or $\alpha$-synuclein was quantified by FRET-based flow cytometry. The protocol was adapted from reference [31]. All experiments were performed using a Digital Analyzers LSRII (IMED) flow cytometer. The fluorescence intensities of the FRET pair (ex: $405 \mathrm{~nm}$; em: 525/50 nm), CFP-fusion proteins (ex: $405 \mathrm{~nm}$; em: $450 / 50 \mathrm{~nm}$ ), and YFP-fusion proteins (ex: $488 \mathrm{~nm}$; em: 525/50 nm) alone were measured. For each experiment, FRET signals of 20,000 cells per replicate were analyzed to differentiate the aggregated protein from the non-aggregated protein. FRET gating was introduced to exclude all of the FRETnegative cells and include the FRET-positive cells. Integrated FRET density (IFD), defined as the percentage of FRET-positive cells multiplied by the median fluorescence intensity of FRET-positive cells, was calculated for all analyses. All experimental data were analyzed using GraphPad Prism 7.0. Plots were fitted to a non-linear sigmoidal curve. The flow-cytometry quantification of protein aggregation was conducted for a minimum of three independent experiments with at least three replicates in each experimental condition.

\section{Measurement of tau seeding in human neuroblastoma cells}

Human neuroblastoma SH-SY5Y cells were cultured in Iscove's modified Dulbecco's medium supplemented with $15 \%$ fetal bovine serum (FBS), $1 \%$ L-glutamine, and $1 \%$ penicillin/streptomycin. Cells were transferred to collagen-coated flat 6 -well plates at a density of $3.0 \times 10^{6}$ cells/well in 1-ml culture medium and incubated at $37{ }^{\circ} \mathrm{C}$ in $5 \% \mathrm{CO}_{2}$. The cells were treated with $\mathrm{A} \beta$ oligomers at $24 \mathrm{~h}$, followed by tau seeds at $48 \mathrm{~h}$. At $72 \mathrm{~h}$, the cells were lysed by sonication in 15\% RIPA buffer and the lysate supernatants were harvested. ELISA was used for quantifying total tau concentration in the lysate supernatants. After normalization of tau concentration, the lysate supernatant was added to tau biosensor cells to measure its seeding capacity. After $48 \mathrm{~h}$, the HEK293T cells were collected, and intracellular tau aggregation was quantified using FRET-based flow cytometry.
Preparation of fluorescently labeled tau (FITC-tau) fibrils Freshly purified tau protein $(50 \mu \mathrm{M}$ in PBS containing $20 \mathrm{mM} \mathrm{DTT}$ ) was incubated with shaking at $37^{\circ} \mathrm{C}$ for $>$ $100 \mathrm{~h}$ until most of the protein was converted into fibrils (a plateau of ThT fluorescent signal monitoring tau aggregation was reached). The tau fibrils were then diluted in a reaction buffer containing $5 \mu \mathrm{M}$ DTT, $10 \mathrm{mM}$ HEPES, pH 7.4, and $100 \mathrm{mM} \mathrm{NaCl}$ to a final concentration of $8 \mu \mathrm{M}$. $0.025 \mathrm{mg}$ of Alexa Fluor 488 NHS Ester per $200 \mu \mathrm{L}$ was added into the reaction mixture and incubated for $1 \mathrm{~h}$ at room temperature and then overnight at $4{ }^{\circ} \mathrm{C}$ with end-over-end rotation. To stop the reaction, the unconjugated dye was quenched with $100 \mathrm{mM}$ glycine in PBS for $1 \mathrm{~h}$. The labeled fibrils were washed extensively with PBS buffer by filtration using a molecular weight cut-off of $10 \mathrm{kDa}$.

\section{Cellular uptake assay of tau fibril seeds}

SH-SY5Y or HEK293T cells were used to measure cellular uptake of tau fibril seeds. $3 \times 10^{4}$ cells were plated in collagen-coated, flat 96-well plates, incubated for $24 \mathrm{~h}$, and then treated with freshly prepared $A \beta, A \beta$ oligomers, or $A \beta$ fibrils. Fluorescently labeled FITC-tau was diluted in Opti-MEM (GIBCO) and added to the cells after an additional 24-h incubation. Tau uptake was monitored using florescence microscopy (ex: 485 em: 520) $24 \mathrm{~h}$ later. After an additional $24-\mathrm{h}$ incubation, cells were harvested after extensive washing with $1 \times$ PBS and flow cytometry was used to quantify the cellular uptake of tau fibril seeds by calculating the percentage of FITCpositive cells.

\section{Electron microscopy (EM)}

Five-microliter aliquots from aggregation reactions were taken at different time points and applied to carboncoated 400-mesh Formvar grids (Electron Microscopy Science), which had been glow-discharged using a Pelco Easy-Glow unit for $2 \mathrm{~min}$ immediately before applying the samples. The samples were wicked off after $1 \mathrm{~min}$, stained with $2 \%$ uranyl acetate for $2 \mathrm{~min}$, and analyzed using a JEOL JEM1200-EX transmission electron microscope.

\section{SDS-PAGE/Western blot}

Cells were lysed by sonication in mild (15\%) RIPA buffer, and the lysate supernatants were harvested by centrifugation for $20 \mathrm{~min}$ at $14,000 \mathrm{rpm}$ in $4{ }^{\circ} \mathrm{C}$. The collected supernatants were dissolved in LDS sample buffer (Thermo Fisher Scientific) and boiled for 5 min prior to loading on NuPAGE 4-12\% Bis-Tris polyacrylamide gels. Following fractionation by SDS-PAGE, proteins were transferred to polyvinylidene difluoride membranes and blocked with 5\% non-fat dry milk in Tris-buffered saline containing $0.1 \%$ Tween 20 (TBST) for $60 \mathrm{~min}$ at 
room temperature. The membranes were incubated for $2 \mathrm{~h}$ at room temperature with anti-human tau monoclonal antibody HT7 (Cell Signaling Technology, Danvers, MA) at a 1:1000 dilution. After 3-min washes with TBST, membranes were incubated with HRP-conjugated [donkey] anti-mouse secondary Anti-thymocyte globulin (Zymed, San Francisco, CA) at a 1:5000 dilution and washed three times again with TBST. The transferred proteins were visualized using an enhanced chemiluminescence (ECL) detection kit (HyGLO Quick Spray Kit, Denville Scientific).

\section{ELISA}

Tau concentration was quantified using an anti-tau ELISA kit (Invitrogen, cat\# KHB0041) according to the manufacturer's instructions. After cell lysis as described above, the resulting supernatant was collected for analysis. Fifty microliters of each sample was analyzed in triplicates.

\section{Primary-neuron culture}

Twelve-millimeter coverslips were placed into the wells of 24-well plates and coated with $500 \mu \mathrm{l} 0.5 \mathrm{mg} / \mathrm{ml}$ polyornithine dissolved in $50 \mathrm{mM}$ sodium tetraborate, $\mathrm{pH}$ 8.3, overnight at $4{ }^{\circ} \mathrm{C}$. After rinsing with $\mathrm{PBS}, \mathrm{pH} 7.4$, the coverslips were coated with $5 \mu \mathrm{g} / \mathrm{ml}$ laminin dissolved in PBS for $2-3 \mathrm{~h}$ at $37^{\circ} \mathrm{C}$ and then rinsed and stored in PBS at $4{ }^{\circ} \mathrm{C}$. Pyramidal hippocampal neurons were isolated and cultured from P0 or P1 postnatal P301S mice (PS19 transgenic mouse line, Jackson Laboratories) as described previously [58]. Briefly, the hippocampi were dissected under a microscope and collected into a $15-\mathrm{ml}$ tube using ice-cold PGB buffer containing $0.2 \mathrm{~g}$ BSA, $0.9 \mathrm{~g}$ glucose in $200 \mathrm{ml}$ PBS, $\mathrm{pH}$ 7.4. The PGB buffer was replaced with a solution of $10 \mathrm{ml}, 0.5 \mathrm{mg} / \mathrm{ml}$ papain, and $0.6 \mu \mathrm{g} / \mathrm{ml} \mathrm{DNAase} \mathrm{(Sigma)} \mathrm{in} \mathrm{PGB,} \mathrm{and} \mathrm{the} \mathrm{tissue} \mathrm{was}$ incubated for $20 \mathrm{~min}$ at $37^{\circ} \mathrm{C}$, rinsed twice with PGB buffer, and dissociated in $2 \mathrm{ml}$ PGB buffer by trituration using a flame-polished, plugged glass pipette. Then, $8 \mathrm{ml}$ of PGB buffer was added and the preparation was centrifuged at $400 \times g$ for $10 \mathrm{~min}$. The supernatants were discarded, and $2 \mathrm{~mL}$ of complete medium $(0.5 \mathrm{mM}$ glutamine, $100 \times$ penicillin/streptomycin, $50 \times$ B-27 in neurobasal medium, Gibco) was added. The cell pellet was dissociated gently using a flame-polished glass pipette, and the cells were counted using a hemocytometer. Seventy thousand to 100,000 cells per well were plated in $0.5 \mathrm{~mL}$ of the complete medium on the previously prepared coverslips. The cells were maintained at $37^{\circ} \mathrm{C}$ in a $5 \% \mathrm{CO}_{2}$ atmosphere. Half of the medium was changed 1-2 times a week.

\section{Tau seeding and immunocytochemistry}

On day 8 of the primary neuron culture, $200 \mathrm{nM} \mathrm{A} \beta$ oligomers in complete medium were added. Twenty-four hours later, $500 \mathrm{nM}$ sonicated tau RD fibrils were added. After an additional 24-h incubation, the cells were fixed in 4\% (v/v) paraformaldehyde in PBS for $15 \mathrm{~min}$, washed three times in PBS, and permeated for $1 \mathrm{~h}$ at room temperature in blocking buffer containing 0.1\% BSA, 5\% donkey serum, $0.3 \%$ Tween-20 in PBS, pH 7.4. The blocking buffer then was removed, and the cells were stained with HT7 or antiphosphorylated tau monoclonal antibody AT8 (ThermoFisher) at 1:1000 dilution in blocking buffer overnight at $4{ }^{\circ} \mathrm{C}$, followed by Alexa-Fluor-555-conjugated donkey anti-mouse secondary antibody (ThermoFisher Scientific) at 1:500 dilution in blocking buffer for $1 \mathrm{~h}$ at room temperature. After washing in PBS, the coverslips were mounted on microscope slides using Prolong Gold Antifade reagent with DAPI (Thermo Fisher Scientific) and imaged using a Leica SP8-SMD Confocal Laser Scanning Microscopy Platform.

\section{Preparation of mouse brain extracts}

Eight-month-old PS19 mice and age-matched WT mice were deeply anesthetized with isoflurane $(0.5-1.5 \mathrm{vol} \%$ in oxygen) and sacrificed by decapitation. Brains were dissected and suspended in 10\% (w/v) ice-cold TBS containing protease and phosphatase inhibitors cocktail (ThermoFisher). The tissue was homogenized at $4{ }^{\circ} \mathrm{C}$ using a probe sonicator (Omni Sonic Ruptor 250) at $30 \%$ power using 25 pulses. Lysates were centrifuged at $21,000 \times g$ for $15 \mathrm{~min}$ to remove cell debris. Supernatants were aliquoted and stored at $-80^{\circ} \mathrm{C}$.

\section{Statistical analyses}

Statistical analyses for two-group comparison were performed by $t$ test calculator (QuickCalcs, GraphPad) with the choice of unpaired $t$ test. For multiple comparison, ordinary one-way ANOVA multiple comparisons were performed using GraphPad Prism software ver. 7.0 (San Diego, CA). All graphs were generated using Prism software.

\section{Supplementary information}

Supplementary information accompanies this paper at https://doi.org/10. 1186/s13195-019-0541-9.

\footnotetext{
Additional file 1: Figure S1. Characterization of $A \beta(1-42)$ preparations. Figure S2. The effect of different $A \beta$ species on tau aggregation in the absence of tau seeds in biosensor cells. Figure S3. When treated A $\beta$ oligomers up to two weeks in the absent of tau seeds, biosensor cells display negligible tau aggregation. Figure S4. A $\beta$ oligomer pretreatment promotes intracellular tau aggregation when biosensor cells are seeded with brain extracts from transgenic mice expressing human P301S-tau. Figure S5. The effects of incubation time on A $\beta$ promoted tau aggregation. Figure S6. A $\beta$ oligomers do not affect $a$-synuclein seeding. Figure S7. Western blot analysis of SH-SY5Y cell lysates treated with A $\beta$ oligomers and tau seeds. Figure S8. ELISA quantification of tau concentrations in SH-SY5Y cell lysates. Figure S9. A oligomers promote the internalization of tau seeds in wild-type mice primary hippocampal neurons. Figure S10. Fluorescence-microscopy images of tau biosensor cells seeded with tau fibrils $24 \mathrm{~h}$ after pretreatment with $A \beta$ oligomers at 100, 200 and 500
} 
nM. Figure S11. Dose-response analysis of the effects of different A $B$ species on tau seeding in tau biosensor cells. Figure S12. Characterization of full-length tau 40 self-assembly. Figure S13. EM image of sonicated tau RD. Figure S14. Pretreatment of $A \beta$ oligomers promotes tau seeding in the presence of lipofectamine. Figure S15. Statistical tests of normal distribution and equal variability of the data.

\section{Abbreviations}

AD: Alzheimer's disease; A $\beta$ : Amyloid $\beta$-protein; CFP: Cyan-fluorescent protein; FRET: Fluorescence resonance energy transfer; GFP: Greenfluorescent protein; RD: Repeat domain; YFP: Yellow-fluorescent protein

\section{Acknowledgements}

We thank the Diamond Laboratory (UT Southwestern) for providing the biosensor cells. This work was supported by National Institutes of Health grants (R01AG060149 and R03NS111482 to L.J; R01AG050721 and RF1AG054000 to G.B). K.A.M. is supported by the UCLA Medical Scientist Training Program (GM08042) and UCLA Chemistry-Biology Interface training grant (USPHS National Research Service Award 5T32GM008496).

\section{Authors' contributions}

$L J$ designed and supervised the research. WSS performed cellular seeding, flow cytometry, SDS-PAGE/Western blot, ELISA experiments, and florescence microscope imaging and analyzed the data. QC and BL purified A $\beta$ protein. WSS and PMS purified tau protein. WSS, QC, and BL characterized the selfassembly of $A \beta$ and tau protein. JD prepared mouse brain extracts and primary neuron culture. JD and WSS performed and analyzed the seeding and tau uptake experiments in primary neuron. WSS, BL, and KAM produced the FITC-labeled tau seeds and performed the tau seed uptake assay. WSS, KAM, $G B$, and $L J$ wrote the manuscript with the input from all authors. All authors read and approved the final manuscript.

\section{Funding}

See acknowledgements.

\section{Availability of data and materials}

Online Content Methods, along with any additional Extended Data display items and Source Data, are available in the online version of the paper; references unique to these sections appear only in the online paper.

\section{Ethics approval and consent to participate}

Not Applicable.

\section{Consent for publication}

Not Applicable.

\section{Competing interests}

The authors declare that they have no competing interests.

\section{Author details}

${ }^{1}$ Department of Neurology, David Geffen School of Medicine, UCLA, 635 Charles E Young Drive South, Los Angeles, CA 90095, USA. ²Departments of Chemistry and Biochemistry and Biological Chemistry, UCLA-DOE Institute, UCLA, Los Angeles, CA 90095-1570, USA. ${ }^{3}$ Brain Research Institute, and Molecular Biology Institute, UCLA, Los Angeles, CA 90095, USA.

Received: 10 April 2019 Accepted: 22 September 2019 Published online: 18 October 2019

\section{References}

1. Bloom GS. Amyloid-beta and tau: the trigger and bullet in Alzheimer disease pathogenesis. JAMA Neurol. 2014;71:505-8.

2. Leinonen V, Koivisto AM, Savolainen S, Rummukainen J, Tamminen JN, Tillgren T, Vainikka S, Pyykkö OT, Mölsä J, Fraunberg M, Pirttilä T, Jääskeläinen JE, Soininen H, Rinne J, Alafuzoff I. Amyloid and tau proteins in cortical brain biopsy and Alzheimer's disease. Ann Neurol. 2010;68:446-53.

3. Ittner LM, Gotz J. Amyloid-beta and tau--a toxic pas de deux in Alzheimer's disease. Nat Rev Neurosci. 2011;12:65-72.

4. Nisbet RM, Polanco JC, Ittner LM, Gotz J. Tau aggregation and its interplay with amyloid-beta. Acta Neuropathol. 2015;129:207-20.
5. Han P, Shi J. A theoretical analysis of the synergy of amyloid and tau in Alzheimer's disease. J Alzheimers Dis. 2016;52:1461-70.

6. Hardy JA, Higgins GA. Alzheimer's disease: the amyloid cascade hypothesis. Science. 1992:256:184-5.

7. Pimplikar SW. Reassessing the amyloid cascade hypothesis of Alzheimer's disease. Int J Biochem Cell B. 2009;41:1261-8.

8. Buckley RF, Hanseeuw B, Schultz AP, Vannini P, Aghjayan SL, Properzi MJ, Jackson JD, Mormino EC, Rentz DM, Sperling RA, Johnson KA, Amariglio RE. Region-specific association of subjective cognitive decline with tauopathy independent of global beta-amyloid burden. JAMA Neurol. 2017;74:1455-63.

9. Frisoni GB, Bocchetta M, Chételat G, Rabinovici GD, de Leon MJ, Kaye J, Reiman EM, Scheltens P, Barkhof F, Black SE, Brooks DJ, Carrillo MC, Fox NC, Herholz K, Nordberg A, Jack CR Jr, Jagust WJ, Johnson KA, Rowe CC, Sperling RA, Thies W, Wahlund LO, Weiner MW, Pasqualetti P, Decarli C. Imaging markers for Alzheimer disease: which vs how. Neurology. 2013;81:487-500.

10. Giacobini E, Gold G. Alzheimer disease therapy--moving from amyloid-beta to tau. Nat Rev Neurol. 2013;9:677-86.

11. Jack CR Jr, Holtzman DM. Biomarker modeling of Alzheimer's disease. Neuron. 2013;80:1347-58.

12. Herrup K. The case for rejecting the amyloid cascade hypothesis. Nat Neurosci. 2015:18:794-9.

13. Bennett RE, DeVos SL, Dujardin S, Corjuc B, Gor R, Gonzalez J, Roe AD, Frosch MP, Pitstick R, Carlson GA, Hyman BT. Enhanced tau aggregation in the presence of amyloid beta. Am J Pathol. 2017;187:1601-12.

14. Louise S. Alzheimer's amyloid fibrils: structure and assembly. Biochim Biophys Acta. 2000;1502(1):16-30.

15. Spires-Jones TL, Hyman BT. The intersection of amyloid beta and tau at synapses in Alzheimer's disease. Neuron. 2014;82:756-71.

16. Busche MA, Wegmann S, Dujardin S, Commins C, Schiantarelli J, Klickstein N, Kamath TV, Carlson GA, Nelken I, Hyman BT. Tau impairs neural circuits, dominating amyloid- $\beta$ effects, in Alzheimer models in vivo. Nat Neurosci. 2019;22:57-64.

17. Vergara C, Houben S, Suain V, Yilmaz Z, De Decker R, Vanden Dries V, Boom A, Mansour S, Leroy K, Ando K, Brion JP. Amyloid- $\beta$ pathology enhances pathological fibrillary tau seeding induced by Alzheimer PHF in vivo. Acta Neuropathol. 2019;10:1007

18. He Z, Guo JL, McBride JD, Narasimhan S, Kim H, Changolkar L, Zhang B, Gathagan RJ, Yue C, Dengler C, Stieber A, Nitla M, Coulter DA, Abel T, Brunden KR, Trojanowski JQ, Lee VM. Amyloid-beta plaques enhance Alzheimer's brain tau-seeded pathologies by facilitating neuritic plaque tau aggregation. Nat Med. 2018;24:29

19. Pascoal TA, Mathotaarachchi S, Shin M, Benedet AL, Mohades S, Wang S, Beaudry T, Kang MS, Soucy JP, Labbe A, Gauthier S, Rosa-Neto P. Synergistic interaction between amyloid and tau predicts the progression to dementia. Alzheimers Dement. 2017;13:644-53.

20. Dickerson BC, Wolk DA, Initia ADN. Biomarker-based prediction of progression in $\mathrm{MCl}$ : comparison of $\mathrm{AD}$ signature and hippocampal volume with spinal fluid amyloid-beta and tau. Front Aging Neurosci. 2013;5:55.

21. Clifford DB, Fagan AM, Holtzman DM, Morris JC, Teshome M, Shah AR, Kauwe JSK. Amyloid and tau cerebrospinal fluid (CSF) biomarker levels in patients with HIV-associated neurocognitive disorder (HAND) compared to levels in HIV-negative (HIV-) patients. Antivir Ther. 2013;18:A74-5.

22. Rafii MS, Lukic AS, Andrews RD, Brewer J, Rissman RA, Strother SC, Wernick MN, Pennington C, Mobley WC, Ness S, Matthews DC. PET imaging of tau pathology and relationship to amyloid, longitudinal MRI, and cognitive change in Down syndrome: results from the Down Syndrome Biomarker Initiative (DSBI). J Alzheimers Dis. 2017:60:439-50.

23. Urmi S, Ashley N, Rakez K. The role of amyloid- $\beta$ oligomers in toxicity, propagation, and immunotherapy. EbioMedicine. 2016:6:42-9.

24. Glabe CG. Structural classification of toxic amyloid oligomers. J Biol Chem. 2008:283:29639-43.

25. Lasagna-Reeves CA, Castillo-Carranza DL, Kayed R. Alzheimer brain-derived tau oligomers propagate pathology from endogenous tau. Sci Rep. 2013;2(700).

26. Inouye H, Sharma D, Goux WJ, Kirschner DA. Structure of core domain of fibril-forming PHF/tau fragments. Biophys J. 2006;90:1774-89.

27. Fitzpatrick AWP, Falcon B, He S, Murzin AG, Murshudov G, Garringer HJ, Crowther RA, Ghetti B, Goedert M, Scheres SHW. Cryo-EM structures of tau filaments from Alzheimer's disease. Nature. 2017;547:185.

28. Bibow S, Mukrasch MD, Chinnathambi S, Biernat J, Griesinger C, Mandelkow E, Zweckstetter M. The dynamic structure of filamentous tau. Angew Chem Int Edit. 2011;50:11520-4. 
29. Stancu IC, Vasconcelos B, Terwel D, Dewachter I. Models of beta-amyloid induced tau-pathology: the long and "folded" road to understand the mechanism. Mol Neurodegener. 2014;9:51.

30. Furman $\mathrm{J}$, Holmes BB, Diamond MI. Sensitive detection of proteopathic seeding activity with FRET flow cytometry. J Vis Exp. 2015(106);e53205.

31. Lim S, Haque MM, Kim D, Kim DJ, Kim YK. Cell-based models to investigate tau aggregation. Comput Struct Biotechnol J. 2014;12:7-13.

32. Jiang L, Liu C, Leibly D, Landau M, Zhao M, Hughes MP, Eisenberg DS. Structure-based discovery of fiber-binding compounds that reduce the cytotoxicity of amyloid beta. Elife. 2013;2:e00857.

33. Bitan G, Teplow DB. Preparation of aggregate-free, low molecular weight amyloid-beta for assembly and toxicity assays. Methods Mol Biol. 2005;299:3-9.

34. Holmes BB, Furman JL, Mahan TE, Yamasaki TR, Mirbaha H, Eades WC, Belaygorod L, Cairns NJ, Holtzman DM, Diamond MI. Proteopathic tau seeding predicts tauopathy in vivo. Proc Natl Acad Sci U S A. 2014;111:E4376-85.

35. Xu Y, Martini-Stoica $H$, Zheng $H$. A seeding based cellular assay of tauopathy. Mol Neurodegener. 2016;11:32.

36. Goedert M, Eisenberg DS, Crowther RA. Propagation of tau aggregates. Molecular Brain. 2017:10:18

37. Gundersen, V. Protein aggregation in Parkinson's disease. Acta Neurol Scand Suppl. 2010;(190):82-7

38. Jellinger KA. Alpha-synuclein pathology in Parkinson's and Alzheimer's disease brain: incidence and topographic distribution--a pilot study. Acta Neuropathol. 2003;106:191-201.

39. Goedert M, Jakes R, Vanmechelen E. Monoclonal-antibody At8 recognizes tau-protein phosphorylated at both serine-202 and threonine-205. Neurosci Lett. 1995:189:167-70.

40. Holmes BB, DeVos SL, Kfoury N, Li M, Jacks R, Yanamandra K, Ouidja MO, Brodsky FM, Marasa J, Bagchi DP, Kotzbauer PT, Miller TM, Papy-Garcia D, Diamond MI. Heparan sulfate proteoglycans mediate internalization and propagation of specific proteopathic seeds. Proc Natl Acad Sci U S A. 2013; 110:E3138-47.

41. Sengupta $U$, Nilson AN, Kayed R. The role of amyloid-beta oligomers in toxicity, propagation, and immunotherapy. Ebiomedicine. 2016;6:42-9.

42. Zhao LN, Long HW, Mu YG, Chew LY. The toxicity of amyloid beta oligomers. Int J Mol Sci. 2012;13:7303-27.

43. Mehta PD, Pirttilä T, Mehta SP, Sersen EA, Aisen PS, Wisniewski HM. Plasma and cerebrospinal fluid levels of amyloid beta proteins 1-40 and 1-42 in Alzheimer disease. Arch Neurol-Chicago. 2000;57:100-5.

44. Kang JH, Korecka M, Figurski MJ, Toledo JB, Blennow K, Zetterberg H, Waligorska T, Brylska M, Fields L, Shah N, Soares H, Dean RA, Vanderstichele H, Petersen RC, Aisen PS, Saykin AJ, Weiner MW, Trojanowski JQ, Shaw LM. The Alzheimer's disease neuroimaging initiative 2 biomarker core: a review of progress and plans. Alzheimers Dement. 2015;11:772-91.

45. Townsend M, Shankar GM, Mehta T, Walsh DM, Selkoe DJ. Effects of secreted oligomers of amyloid beta-protein on hippocampal synaptic plasticity: a potent role for trimers. J Physiol. 2006;572:477-92.

46. Di Scala C, Yahi N, Boutemeur S, Flores A, Rodriguez L, Chahinian H, Fantini J. Common molecular mechanism of amyloid pore formation by Alzheimer's beta-amyloid peptide and alpha-synuclein. Sci Rep-Uk. 2016;6:28781.

47. Tanokashira D, Mamada N, Araki W. The neurotoxicity of amyloid beta-protein oligomers is reversible in a primary neuron model. Mol Brain. 2017;10:4.

48. Busche MA, Wegmann S, Dujardin S, Commins C, Schiantarelli J, Klickstein N, Kamath TV, Carlson GA, Nelken I, Hyman BT. Tau impairs neural circuits, dominating amyloid-beta effects, in Alzheimer models in vivo. Nature Neuroscience. 2019;22:57.

49. Crary JF, Trojanowski JQ, Schneider JA, Abisambra JF, Abner EL, Alafuzoff I, Arnold SE, Attems J, Beach TG, Bigio EH, Cairns NJ, Dickson DW, Gearing M, Grinberg LT, Hof PR, Hyman BT, Jellinger K, Jicha GA, Kovacs GG, Knopman DS, Kofler J, Kukull WA, Mackenzie IR, Masliah E, McKee A, Montine TJ, Murray ME, Neltner JH, Santa-Maria I, Seeley WW, Serrano-Pozo A, Shelanski ML, Stein T, Takao M, Thal DR, Toledo JB, Troncoso JC, Vonsattel JP, White CL 3rd, Wisniewski T, Woltjer RL, Yamada M, Nelson PT. Primary age-related tauopathy (PART): a common pathology associated with human aging. Acta Neuropathol. 2014;128:755-66.

50. Jellinger KA, Alafuzoff I, Attems J, Beach TG, Cairns NJ, Crary JF, Dickson DW, Hof PR, Hyman BT, Jack CR Jr, Jicha GA, Knopman DS, Kovacs GG, Mackenzie IR, Masliah E, Montine TJ, Nelson PT, Schmitt F, Schneider JA Serrano-Pozo A, Thal DR, Toledo JB, Trojanowski JQ, Troncoso JC, Vonsattel JP, Wisniewski T. PART, a distinct tauopathy, different from classical sporadic Alzheimer disease. Acta Neuropathol. 2015;129:757-62.
51. Carrillo-Mora P, Luna R, Colin-Barenque L. Amyloid Beta: multiple mechanisms of toxicity and only some protective effects? Oxidative Med Cell Longev. 2014;795375:15.

52. Kayed R, Lasagna-Reeves CA. Molecular mechanisms of amyloid oligomers toxicity. Adv Alzh Dis. 2013;3:67-78

53. Di Scala C, Yahi N, Boutemeur S, Flores A, Rodriguez L, Chahinian H, Fantini J. Common molecular mechanism of amyloid pore formation by Alzheimer's beta-amyloid peptide and alpha-synuclein. Sci Rep-Uk. 2016;6:28781.

54. Qi RX, Luo Y, Wei GH, Nussinov R, Ma BY. A beta "stretching-and-packing" cross-seeding mechanism can trigger tau protein aggregation. J Phys Chem Lett. 2015:6:3276-82.

55. Cao Q, Shin WS, Chan H, Vuong CK, Dubois B, Li B, Murray KA, Sawaya MR, Feigon J, Black DL, Eisenberg DS, Jiang L. Inhibiting amyloid-beta cytotoxicity through its interaction with the cell surface receptor LilrB2 by structure-based design. Nat Chem. 2018;10:1213-21.

56. Seidler PM, Boyer DR, Rodriguez JA, Sawaya MR, Cascio D, Murray K, Gonen T, Eisenberg DS. Structure-based inhibitors of tau aggregation. Nat Chem. 2018;10:170-6

57. Li B, Ge P, Murray KA, Sheth P, Zhang M, Nair G, Sawaya MR, Shin WS, Boyer DR, Ye S, Eisenberg DS, Zhou ZH, Jiang L. Cryo-EM of full-length a-synuclein reveals fibril polymorphs with a common structural kernel. Nat Commun. 2018:9(1):3609.

58. Beaudoin GM 3rd, Lee SH, Singh D, Yuan Y, Ng YG, Reichardt LF, Arikkath J. Culturing pyramidal neurons from the early postnatal mouse hippocampus and cortex. Nat Protoc. 2012;7:1741-54.

\section{Publisher's Note}

Springer Nature remains neutral with regard to jurisdictional claims in published maps and institutional affiliations.
Ready to submit your research? Choose BMC and benefit from:

- fast, convenient online submission

- thorough peer review by experienced researchers in your field

- rapid publication on acceptance

- support for research data, including large and complex data types

- gold Open Access which fosters wider collaboration and increased citations

- maximum visibility for your research: over $100 \mathrm{M}$ website views per year

At $\mathrm{BMC}$, research is always in progress.

Learn more biomedcentral.com/submissions 